\title{
Phenomenal roles: a dispositional account of bodily pain
}

\section{Simone Gozzano ${ }^{1}$}

Received: 24 August 2020 / Accepted: 3 April 2021 / Published online: 20 April 2021

(C) The Author(s) 2021

\begin{abstract}
In this paper I argue that bodily pain, as a phenomenal property, is an essentially and substantial dispositional property. To this end, I maintain that this property is individuated by its phenomenal roles, which can be internal -individuating the property per se- and external -determining further phenomenal or physical properties or states. I then argue that this individuation allows phenomenal roles to be organized in a necessarily asymmetrical net, thereby overcoming the circularity objection to dispositionalism. Finally, I provide reasons to argue that these roles satisfy modal fixity, as posited by Bird, and are not fundamental properties, contra Chalmers' panpsychism. Thus, bodily pain can be considered a substantial dispositional property entrenched in non-fundamental laws of nature.
\end{abstract}

Keywords Dispositions · Phenomenal properties · Categorical properties · Laws of nature $\cdot$ Panpsychism $\cdot$ Phenomenal roles

\section{Dispositions and phenomenal states}

The goal of this paper is to defend the thesis that having bodily (or sensory) pain, a mental property of a phenomenal sort, is an essentially and substantial dispositional property. In order to argue for this, I shall show that pain should be characterized in terms of roles (as dispositional), that these roles are necessary for characterizing it (as essentially dispositional) and that, in virtue of these roles, this phenomenal property has causal efficacy (its dispositional nature is substantial). ${ }^{1}$ The roles that individuate pain are the very same phenomenal features used to characterize it.

\footnotetext{
1 If one advocates the identity view (as Martin and Heil 1999 do), then this paper is an attempt to show how the pure powers view merges with a paradigmatic quality such as pain (see Taylor, 2013, 2018).
}

\section{This article belongs to the topical collection on New Foundations of Dispositionalism, edited by} Andrea Raimondi and Lorenzo Azzano.

Simone Gozzano

simone.gozzano@univaq.it

1 Università Degli Studi Dell'Aquila, Viale Nizza 14, 67100 L'Aquila, Italy 
The motivation that prompts this thesis lies in challenging the view, notably held by Block (1980) and Chalmers (1996, 2010), that phenomenal properties in general cannot be analyzed in functional terms. And that the impossibility of "functionalizing" (cfr. Kim, 2005) these properties is equivalent to the idea that these properties are not dispositions, since dispositions are individuated in terms of their causal (or functional) roles. ${ }^{2} \mathrm{Kim}$, whose strong physicalist inclinations are known, was skeptical about the possibility of functionally individuating phenomenal properties, due to the problem of qualia inversion: "color qualia do not supervene on behavior [...] If that is true, qualia are not functionally definable; they are not task-oriented properties" (Kim, 2005: p. 170). Is the path to functionalizing phenomenal properties already blocked at the outset? As I said, I will limit myself to bodily pain. Qualia inversion has rarely been applied to sensory pain and it is far from clear how it would apply. Vice versa, the skeptical locus for the functionalization of pain involves zombies. In what follows, I will specify the roles that individuate pain as a phenomenal property, so zombies are not the problem at stake. As for inversion, the main difference with respect to the case of color is that inverting, say, the relation between pain intensity on the one side and stimuli intensity or bodily damage on the other would result in losing, at least part of, the biological function of pain. A function, as we shall see, which is crucial for pain. ${ }^{3}$ Lewis (1980) has tried to invert pain with thirst, arguing that these feelings occur in relation to the physiological characteristic of a population, and Horgan (1984), discussing Lewis' case, has argued that pain calls for a double theory -one in which functionalism is flanked by a type identity theory of mental and neural states - when phenomenality is to be considered. That would amount to accepting a sort of categoricity for these properties. I think I can avoid both conclusions: if the roles of pain are described in the finest possible details, pain is completely individuated and there would be no need to limit the individuation to an a priori set population or physical realization, even if it may turn out to be so limited. So, even if the argument I am presenting is limited to the case of bodily pain, it still shows that for some phenomenal property functionalization is possible. ${ }^{4}$ And the argument uses the phenomenal component of our consciousness to individuate phenomenal properties themselves. In the recent past, phenomenal components have been of help in providing analyses and theories of intentionality, another crucial element in the mind. ${ }^{5}$ So, it is time to consider how phenomenal features can contribute to individuating some of the phenomenal properties themselves.

Before getting into the details of my proposal, it is important to set the stage with respect to two issues: the first is what dispositions are and the role of the mental in this metaphysical framework; the second is whether phenomenal properties as

\footnotetext{
${ }^{2}$ One may also deny that phenomenal properties are essentially dispositional by arguing that these properties are solely role occupants, and nothing can be said about the properties themselves, a position Lewis dubbed "Ramseyan humility" (Lewis, 2009). As a natural consequence, this latter view takes zombies to be possible, where a zombie is dispositionally identical to a conscious individual, differing only categorically by lacking consciousness.

3 See Sect. 5 for a first argument.

4 Both Umut Baysan and Paul Noordhof pointed this problem out to me. I wish to thank both of them.

5 See Kriegel (2012), Mendelovici (2018), Schwitzgebel (2002), Gozzano (2019a).
} 
dispositions, are fundamental powers. Dispositions: a property is dispositional if it necessarily confers on its bearers a specific propensity or power toward some specific manifestation. Many dispositions confer more than one power, so some dispositions confer clusters of powers. ${ }^{6}$ There is considerable agreement that the relation between dispositions and manifestations, or between the conditions for manifestation and those manifestations themselves, individuate what dispositions are and that they should be conceived in causal terms (Bird, 2007a; Mumford, 1998; Shoemaker, 1980). So, that dispositions do tend towards their manifestations is a platitude accepted by everyone in the field (cfr. Tugby, 2013). However, on how dispositions tend towards their manifestations, philosophers diverge. They tend because of stimuli, (Carnap, 1936, Choi, 2012), or by habit (Fara, 2005), or by naturally facilitating them (Vetter, 2015), or in virtue of interactions with some partners (Heil, 2012; Molnar, 2003).

Dispositions are frequently contrasted with categorical, or qualitative, properties. The latter are individuated as the properties that essentially qualify their bearers by virtue of being identical or distinct from other categorical properties. A categorical property is one that is not necessarily connected to any specific manifestation, contrary to what a dispositional property is, and this is their crucial difference. So categorical properties are not identified by their causal relations, because the powers that categorical properties bestow on their bearers are contingent (Wang, 2016). Having the property of being spherical, supposedly a categorical property, does not necessarily lead to any "sphere-like" behavior on the part of the bearer, such as rolling straight on a flat, inclined surface, because there is nothing about being spherical that determines the behavior of its bearers, even if the bearers may behave in this way. ${ }^{7}$ Categorical properties are considered as quiddities (Armstrong, 1997; Schaffer, 2005); either bare quiddities, intrinsically differentiated by being different, or qualitative quiddities, distinguished by their qualities while leaving structures and causal dispositions untouched (Hildebrand, 2015).

Not everyone agrees that the dispositional / categorical distinction is sound: Martin (2008) and Heil (2003), and many others (Ingthorsson, 2013; Carruth, 2016; Jacobs, 2011; Taylor, 2018) insist that the distinction is a superficial one, and that pure powers (i.e., dispositions) and qualitative properties (categorical) should be identified. ${ }^{8}$ But most still think that a distinction needs to be drawn. A consequence of the stance one has with respect to this distinction is whether to be a monist-only one kind of property exists — or a dualist. Among monists, all varieties are admitted: the identity theory — defended by Martin and Heil (1999)- claims there is only one kind of property because all properties are both dispositional and categorical; pandispositionalism — advocated by Mumford and Anjum (2011)- takes all properties to be dispositions, and categoricalism — perhaps Armstrong and Lewis herald this

\footnotetext{
${ }^{6}$ For instance, elasticity, as a disposition, confers the powers of expansion, retraction, and so on. Some argue that dispositions are simply powers.

7 Leaving questions of necessitation aside, on these see Gozzano (2020a).

8 According to these authors, dispositions are just pure powers. So, they do not distinguish between the two concepts.
} 
view- maintains that all (real) properties are categorical. ${ }^{9}$ Alternatively, one can be a dualist - like Ellis (2001) and Bird (2007a)- allowing that properties be either dispositional or categorical, but not both.

In the present discussion on dispositions, we should also consider the issue of the fundamentality of powers, and here we get to the second issue to be set. We have said that dispositions can be conceived as the tendencies of their bearers toward certain manifestations. But why are the bearers so disposed? Because, dispositionalists reply, necessarily, if bearers have a certain dispositional property, they have the constitutive powers of that property, and these determine the bearer's causal relations. Are these powers ubiquitous? Bird (2016) initially suggested that powers can be found only at the fundamental level of reality, where bearers do not need further bearers to be exemplified, thus determining fundamental dispositions. So, electrons are essentially negatively charged, and nothing else is responsible for them being so. If we get to non-fundamental levels, non-fundamental dispositions supervene on fundamental ones and on their powers. So, powers are present only at the fundamental level, thus are not ubiquitous.

In a more recent paper, though, Bird (2018) has suggested that there are also nonfundamental powers, in particular evolved powers and mental powers. Given the pivotal role played by phenomenal properties in the philosophy of mind, I shall consider whether these properties are powers, that is, essentially dispositional properties, albeit non-fundamental ones, a position I will contrast with panprotopsychism. In this way, the mental property of being in pain would be individuated by the phenomenal roles that it plays, considered in dispositional terms. So, we are back to my opening remarks: I am defending a form of functionalism, one that applies to a specific phenomenal property, pain.

Different paths could be taken to argue for my thesis. One could argue, along with Heil and Martin, that given that phenomenal properties are properties enough, and properties are both dispositional and categorical, then phenomenal properties are also dispositions and not just categorical properties. As a matter of fact, this view has been pursued by Hedda Hassel Mørch, who has argued "that phenomenal properties are intrinsically powerful, which is to say that they produce or bring about their effects, or make them happen, in virtue of their intrinsic character alone" (Mørch, 2017: p. 303). ${ }^{10}$ By the same token, one could take Mumford's pandispositional view, and argue as follows: if phenomenal properties are bona fide properties, since all properties are dispositions, phenomenal properties are dispositions as well. These two strategies, in my view, would beg the question of the phenomenalist, as we may call anyone who defends the purely categorical interpretation of phenomenal properties. So, I wish to give a more reasoned and articulated defense of the thesis.

\footnotetext{
9 See Contessa (2019) for a similar reconstruction.

${ }^{10}$ I owe the suggestion of considering the interesting work by Mørch to a referee for this journal, whom I thank. Relatedly, Mørch (2020) mentions an insightful work by Langsam (2011) who explores a similar path. In this paper, however, I cannot do full justice to these works.
} 
This paper has two main parts. In the first part, I will tackle the question: is pain as a phenomenal property a disposition? In Sect. 2 I will set out the dispositional framework that I will consider in the paper; in Sect. 3 I will describe how to individuate pain in dispositional terms, and in Sect. 4 I will test this individuation against the main obstacle for the dispositional view: the circularity objection, showing why my proposal fares better than other options. The second part addresses a second question: is pain as a phenomenal property a power on its own? In Sect. 5 I defend the idea that pain is a non-fundamental yet causally efficacious dispositional property. Finally, in Sect. 6, I argue that the causal efficacy of pain should be assessed in light of its biological role, a role that figures in biological laws and principles.

\section{Pain as disposition-individuation}

Bird (2016) takes fundamental dispositional properties to be those properties that are: (i) not realized by other (fundamental) properties or states; (ii) individuated by necessary relations; (iii) constitutive elements of laws of nature, hence sparse. Let's consider these conditions in some details as applied to bodily pain. Condition (i) has that pain, inasmuch it is realized by other properties, such as physical properties, is a non-fundamental property. I adhere to this view: pain is based on or grounded in physical properties, an issue to which I will return in the second part of the paper, providing an argument in support of this view. Condition (ii) is cashed out in terms of modal fixity - following Bird, the necessary relations holding among phenomenal properties Ps are such that the phenomenal roles that individuate the phenomenal property $\mathrm{P}$ holds stable across possible worlds. Typical difficulties for dispositionalizing (or functionalizing) pain can be traced back to Lewis' famous paper "Mad pain and Martian pain" (Lewis, 1980). The gist was that causal roles do not necessarily identify pain because the Mad, being "hooked up differently", is such that his pain is caused by mild physical exercise and causes finger snapping, thus demonstrating that the same phenomenal property can take on different roles. At the same time, we have the Martian, whose causal roles are similar to a typical human, but whose brain is altogether different, thereby also precluding the type-physicalist path. Not to mention the case of Mad Martian pain, where both roles and realizers are different. To sidestep the Mad case, we need to find necessary connections for the individuation conditions of pain states. ${ }^{11}$ To sidestep the Martian case, multiple realizability must be granted. If both these results are achieved, Mad Martian pain is sidestepped as well. Finally, condition (iii) says that to be sparse or natural, a property should figure in a law of nature, even a non-fundamental one, an issue that will be considered in the final section.

Dispositions are individuated by the structural and causal roles their bearers necessarily enter into: whereas structural roles are those that capture what a disposition is in itself, causal roles are determined by and determine further states or properties. In the case of pain, I argue that the roles that individuate pain are the phenomenal

$\overline{11}$ For a discussion on the relation between these cases and causal efficacy, see Baysan (2018). 
ones, without this committing myself to say anything about how one feels in having pain. ${ }^{12}$ Basically, phenomenality is here used in a heuristic way, as a strategy to keep track of the causal profile (what causes $x$ and what $x$ causes) that conforms to the analytical profile of our commonsensical concept of pain. Phenomenal roles are those roles that have further phenomenal states as structural and causal relata. Projected onto the debate on the metaphysics of properties, this should not come as a surprise: the manifestations of dispositions are dispositions themselves, and this holds also in phenomenal terms. To give an example: my being upset causes me to be shaken up; my crying causes your compassion, where all these relata are phenomenal properties. In the case at hand, I invite you to focus only on the phenomenal properties that pain as a power (or disposition) confers on its bearers. How is pain to be interpreted in dispositional terms?

Pain is phenomenologically dispositional in the following sense: it is caused by phenomenologically salient properties, it is in itself the manifestation of our sensitivity to these properties and, in turn, it causes phenomenological reactions such as self-care, self-compassion, and other phenomenal properties that I consider below. So, pain is both the manifestation of our sensitivity toward some salient property and our readiness to engage in self-care. The phenomenal dispositionality is conceived in terms of phenomenal roles, which characterize pain necessarily, according to the view that dispositions fix their roles necessarily. It is time for me to say what these roles are.

\section{Phenomenal roles for pain}

I will divide the phenomenal roles that individuate pain into internal and external ones. The phenomenal roles that make pain the phenomenal state it is, and so are necessary to it, are the internal phenomenal roles.

Internal phenomenal roles. These roles are both structural and causal in that they establish the nature of feeling pain, and so are internal features of pain and determine the causal relations which pain can enter into. I consider three roles of this kind: intensity, location, and dynamics. Intensity: the property of feeling pain is a scalar property that ranges from slight to unbearable. Location: the property of feeling pain is represented and localized as a point, area, or volume on or in the body. Dynamics: the property of feeling pain can be qualified as "burning", "throbbing", "pulsing" and the like. ${ }^{13}$ These gerundival adjectives mark the classificatory function that dynamics play, and one component of such dynamics is the duration of pain. ${ }^{14}$ Internal phenomenal roles causally determine further phenomenal roles,

\footnotetext{
12 I take this view compatible with a representationalist or a higher-order theory of consciousness.

13 With Bayne (2010), one could argue that the three phenomenal roles individuate the mereological parts composing the unity of the phenomenal experience of pain.

14 Not all adjectives related to pain are gerundival; there are some, such as "sharp" or "dull", which are not. Nevertheless, there is a gerundival component in these as well. There is a further dimension in which pain is dynamic: pain has a duration and can move, expand, pulse, and such dynamics can determine a sort of epistemology. This dimension might be reducible to the other two components-intensity and location-but the gerundival aspect cannot be. See Tye (1989) for a modified adverbial treatment.
} 
which are not internal to pain. These are the external phenomenal roles, those that pick out only those causal relations in which pain is embedded.

External phenomenal roles. There are two external roles: stimuli detection and self-care. Stimuli detection: highly salient stimuli, that signal damaging or potentially damaging stimuli, cause the occurrence of the property of having pain. Expressed in dispositional terminology: stimulus detection is the dispositional component that has the occurrence of pain as its manifestation. So, phenomenality tracks down the relevant elements in the causal chain that we recognize as composing the overall causal profile of pain. These stimuli may well occur because of a dispositional partner - a knife cutting the skin, a rock breaking a bone-or because of a sudden internal trigger - an increase in gastric acid that determines a burning ache in the stomach. The crucial nature of these stimuli is that they reorient our attention by virtue of their saliency. Note that saliency is definitely a phenomenological concept: $x$ is salient if it stands out, or looks more evident, with respect to the phenomenological surrounding the subject is immersed in. ${ }^{15}$ Self-care: caused by the tokening of internal phenomenal roles, self-care is the property of attending and paying attention to the body location in which pain is felt or represented to be, in line with its intensity and dynamical nature. ${ }^{16}$ This self-care may come down to protecting, massaging, avoiding further contact, and all the possible ways in which pain is cared for. ${ }^{17}$ So, considered with respect to the detection of salient stimuli, pain is a manifestation; but with respect to self-care, pain is a stimulating condition or dispositional partner. Putting all these specifications together, we find that both internal and external phenomenal roles determine the overall causal profile or the dispositionality of pain: being caused by phenomenologically salient properties or states; determining our sensitivity to them in terms of intensity, location, and dynamics; and causing self-care states. In this sense, its external phenomenal roles are caused by its internal phenomenal roles. Clearly, external phenomenal roles may bring about nonphenomenal roles, i.e., purely physical roles, an issue to which I will return.

It should be further noticed that the internal and external roles that are part of the dispositional profile of pain also have internal relations: a proportionality relation and a directionality relation. The proportionality relation is established between the felt intensity and level of self-care, such that the more intense the pain is, the more

\footnotetext{
${ }^{15}$ Saliency has been pinned down in physiological terms: "It is important to highlight that nociceptive specific neurons are often defined as such because they respond to high-intensity but not to low-intensity somatosensory stimuli" (Iannetti \&, Mouraux 2010: p. 4). So, (1) they get their individuation in virtue of their role; (2) high intensity strongly correlates with saliency.

16 The case of Putnam's "Superspartan" is not an issue: the attention directed toward or away from the painful spot is a sufficient condition for the role being fulfilled. I won't discuss the property of pain location.

${ }^{17}$ Self-care is not necessarily caused by an occurring pain. For instance, self-care may assume some of the following forms. Anxiety: when someone represents herself as at risk of pain; desire, when she represents herself as enjoying the prospect of being relieved from the pain she presently feels; hope, when she represents herself as shielded from pain; undesirability, when she represents herself as at risk of suffering from pain; expectation, when she represents herself as having taken a pain killer while suffering pain.
} 
attention it receives. ${ }^{18}$ From a phenomenological point of view, pain and attention should not be considered to be one and the same property. The fact that one can try to refrain from paying attention to a felt pain and concentrate on something else shows the non-coincidence of the two conditions. This, however, doesn't mean that the proportionality relation doesn't hold: the intensity of attention required to modulate the feeling of pain must surpass the intensity of the pain itself, thus demonstrating proportionality from another perspective. ${ }^{19}$ The directionality relation holds between the point, area, or volume in which the pain is represented and the corresponding area toward which self-care is devoted, even if the bearer knows that this pain might be delusory. Consider phantom limb pain: self-care may be devoted to a missing limb, a situation that leads to the frustration typically reported by those who suffer from this condition. Nevertheless, the subject in some way still attends to the missing limb. ${ }^{20}$ The relations between internal and external phenomenal roles are therefore relations belonging to the property of feeling in pain, thus relations internal to it. So, internal roles are those that sets what pain is in itself, external roles are those caused by the internal ones and determining further non phenomenal roles. ${ }^{21}$ Summing up: if a phenomenal state plays the three internal and the two external roles and is embedded in the internal relations described, it is pain.

One may object whether the roles for pain are necessary and sufficient for it. ${ }^{22} \mathrm{On}$ the side of necessity, it seems that moral or emotional pains do not have location. True, but I limited my analysis to bodily pain, thus excluding these kinds of pain from discussion, because these depend on further moral values. But, the objection continues, not all bodily pains determine self-care, as is the case with the masochist. I don't think this is the case. The masochist is interested in the control of the sensation of pain, not in having pain per se. No masochist is happy in being involved, say, in a car accident, even if it may determine great pain. The reason is that that pain is not under the masochist's control. What the masochist is after, is the balance between pain and pleasure, and the use of pain as a trigger for pleasure. So, the masochist is self-caring about the pain, by administering it as long as it gives her pleasure. ${ }^{23}$ A different case is pain asymbolia, a condition in which subjects are on average in locating pains, but they are not "affected by it", that is, they do not take the intensity to be such to justify self-care (Grahek, 2007). Such a case, of physical origin, fits with this dispositional proposal because it indicates that there is a

\footnotetext{
18 In imagining a spectrum inversion, this proportionality could be among the inverted variables. But it would allow us easily to ascertain that the subject is inverted.

19 Obviously, there are phenomena of adaptation and habituation that make the proportionality relation non-linear. I skip this issue, so avoiding complicating the model.

20 On this see Ramachandran (1998).

21 Armstrong argues that pain is a categorical property, and he characterizes these properties thus: "Properties are self-contained things, keeping themselves to themselves, not pointing beyond themselves to further effects brought about in virtue of such properties" (Armstrong, 1997: p. 80). In showing that the internal roles of pain are intrinsically pointing toward the external ones, I show that pain cannot be categorical in Armstrong's sense.

22 A referee for this journal, whom I thank, pressed me on this point.

23 On the case of masochism see Goldstein (1983), Klein (2014); on pain unpleasantness see Bain (2013), and Massin (2017).
} 
dispositional mask or a dispositional fink somewhere in the neural pathways. That is to say, some mechanism is in play such that the usual manifestation, caring about pain, is prevented from occurring or its manifestation is masked before it can occur. Hence, the necessity condition is not affected because in this case different conditions from the one that set the necessary relation are in play. ${ }^{24}$ Are the roles sufficient for individuating pain? One may observe that in having pleasure one is selfcaring to herself or that the usual reading of the masochist fits with the condition. But the self-care I'm pointing out is a state which is life-preserving, as I will stress in Sect. 6, and this excludes both the masochist and the hedonist: they are not trying to remove or avoid the sensation when they are self-caring, rather they are modulating it to get the amount they like.

So far, I have argued that pain has internal and external phenomenal roles, that these roles essentially individuate it as a manifestation of our capacity to detect salient stimuli and as a trigger for self-care states, and that these roles have internal relations of proportionality and directionality. All this considered, bodily pain is robustly captured as a dispositional property, which was my first aim.

However, considering pain to be a dispositional property is not enough to fully individuate this property as such. The fact is that dispositional properties are individuated by their structural relations with other dispositional properties, and this sort of holistic individuation is a thorny issue for this view. Why should my proposal fare any better in this respect?

\section{Individuating pain: a relational view}

Swinburne (1980: p. 313) has argued that if properties are potentialities then the only way to recognize them is by observing further properties that actualize them; since all properties are potentialities, the regress is infinite. Consequently, individuating pain as a disposition through a net of other dispositions would not be viable. More recently, Lowe (2006: p. 138; 2012) has argued that properties of kind K cannot be individuated only by other properties of kind $\mathrm{K}$, because this would lead to massive circularity. Bird states Lowe's critique as follows: "The identity of this property is what the set of relationships was supposed to settle. Yet the nature of this set of relationships is dependent on the identities of its relata, which ex hypothesis have not yet been settled" (Bird, 2007b: p. 524). This is the circularity objection, one that vexes any dispositional theory.

Bird's way out of the circularity predicament is to have an asymmetrical net, one that would allow precise individuations by blocking circularity (Bird, 2007b). However, Lowe replies, there is no guarantee that such asymmetry is necessarily the case, so the net can at most guarantee identification but not individuation, because essence is not given by a position in a net. (Lowe distinguishes individuation-what is the essence of $\mathrm{x}$-from identity-under what condition(s) $\mathrm{x}$ and $\mathrm{y}$ are one and the same). In a nutshell: the asymmetrical net of Bird is just a contingent one.

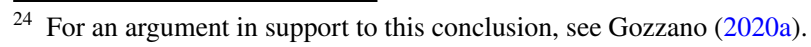


Lowe's critique has traction as long as one accepts that essences are not revealed by causal relations. If one takes essences to be identical with the causal relations that necessarily characterize a property, the critique loses its force. Yates (2018) has argued that the way out of Lowe's difficulty is to have one kind of property in play to anchor a different kind of property. This is the lesson of functionalism, where complex mental properties are individuated thanks to physical properties that lie outside of the causal structure that individuates complex mental properties. ${ }^{25}$

One may apply Yates' solution to the individuation of dispositions (pure powers, in his terminology): assume mental properties to get their individuation conditions from both mental and non-mental properties (physical ones). "The identities of the inputs and outputs [which are physical properties] are not determined by their places in the relevant psychological causal structure, and so can serve to individuate the mental properties whose identities are so individuated" (Yates, 2018: p. 4532).

However, because of multiple realization, input and output can be properties of a different type. This was Lewis' lesson on pain when considering the Martian case, where the Martian roles are the same as those of human beings, but their realizers are type-different. If the input and output determine the identity conditions for mental properties, then, since the type of properties for which input and output are the tokening could change, the individuation of mental properties could change as well. So, this solution is blocked. One (difficult) way out of this conundrum would be to consider these physical properties disjunctive, where the disjuncts are type-different realizers. However, multiple realization is open so, the disjunctive property would be open and potentially endless. Therefore, we wouldn't know which properties were the "individuators" (as Lowe would say) of any property. So, Yates' strategy won't work if the anchors are taken as physical properties. An alternative could be to take behavioral properties as the necessary physical properties, interpreting these behavioral properties as overall actions rather than as purely physical movements (Hornsby, 1986) ${ }^{26}$ In this way, since an action is not a phenomenal property, one would have a non-phenomenal property anchoring the phenomenal property of feeling pain. However, it is unclear whether it is always possible to conceive of actions as properties that are not in the relevant psychological causal structure, because they are clustered in psychological terms rather than in purely behavioral-i.e., physical kinematic-terms. For instance, one person may react to pain in some way, while another one reacts differently: these would both be reactions to pain, so would both count as actions belonging to the same action-type. However, their classification as reactions to pain depends on a psychological reading, not on a physical one. This means that the physical component could be different, putting us in the same predicament as before. So, not even this view is viable.

I propose to individuate pain by considering only the phenomenal roles. Further, I propose to follow Bird's attempt to resolve this conundrum, by appealing to asymmetrical nets. How can we assure that the asymmetry is necessary? Lowe argues

\footnotetext{
${ }^{25}$ In this particular case, Yates proposes non-fundamental qualitative properties as a means for the proper individuation of fundamental physical properties.

26 As suggested by David Yates in conversation, whom I thank.
} 
that one way out of the circularity objection is to have self-individuating properties. He considers the number 0 and the empty set as cases in point. Take 0 , which allows us to stop any further regress in the definition of natural numbers by providing a base for applying the recursive successor function. Number 0 is self-individuating because "it is the sole natural number with no predecessor" (Lowe, 2006: p. 229), where we may take a predecessor to be the converse of a successor. However, both 0 and the empty set are abstract objects. Is there an analogous condition when it comes to properties that are realized by physical properties? Here I propose to consider nomological necessities.

In nature, many properties have limiting points. Hardness ranges from the hardest material, diamond, to the softest, talc; speed-relative to a frame of referencefinds its limits at rest and the speed of light; temperature ranges from absolute zero to Planck temperature. These limits are either fundamental and fixed, like speed; fixed but not fundamental, like temperature; or non-fundamental but univocally realized, like diamond. They provide natural anchors: since such limits on properties of kind $\mathrm{K}$ exist, the net can be oriented by K-type properties alone, in analogy with the asymmetry determined for the natural numbers by 0 . I argue that pain as a physically realized phenomenal property also has physical limits on intensity. The lower limit is the pain threshold: "the least stimulus intensity at which a subject perceives pain" (as reported in the website of the International Association for the Study of Pain-IASP), where "perception" comes down to the experience of the subject. The upper limit is so-called pain tolerance: "The maximum intensity of a pain-producing stimulus that a subject is willing to accept in a given situation" (IASP, 1986). A better and purely phenomenological definition would be: a painful condition such that no further stimulus can worsen the painful condition (possibly due to physiological mechanisms). In this way, we avoid any reference to "willing to accept" on behalf of the subject.

The ladder of pain intensity is thus one that is naturally and nomically oriented by the values that the intensity of pain can reach. When minimum and maximal intensities have been established and fixed, these are fixed points that can orientate the net and anchor the other intensities in a non-circular way. These phenomenal properties are thus self-individuating: the lowest level of pain is the sole phenomenal property-stimulated by highly salient stimuli and causing self-care phenomenal states - that does not have any less intense same-kind state. It doesn't need anything else in order to be the phenomenal condition it is because it is part of its essence to be a state that is minimally felt as the one that is stimulated (by salient stimuli) and manifested (in self-care). Since intensity has minimal and maximal limits, it provides a non-circular method of individuation.

Note, it is not necessary that one feels minimal pain as such. That is, nothing hinges essentially on the possibility that individuals identify a given phenomenal state as the one that is the minimally felt pain in an absolute sense. After all, each individual may have a different threshold and the threshold of any individual may change over time. However, these eventualities do not change the concept of threshold. So, this is not an epistemological issue. What is essential, rather, is the metaphysical point: there is a finite range of properties that are considered to constitute pain, and this range has limiting points: a minimum and a maximum. It is sufficient 
that the limits are metaphysically established and that provide a structure that is specific (the only state that is determined by salient stimuli and determines self-care). A limit in this sense is a type threshold, an idea that can be clarified as follows: one can take away parts of a lump of gold and still have some gold. When you get to an atom of gold, you cannot take away any part of the atom and still have gold, because you would change the category to which the entity belongs. So, when you have an atom of gold you have reached the type threshold for being gold. Perhaps, in the case of pain this threshold is vaguer, but it is a threshold, nevertheless. ${ }^{27}$

However, a tentative hypothesis for what satisfies the threshold of pain can be given. This should correspond to the minimal felt bodily disturbance. ${ }^{28}$ Itches come to mind: these are phenomenally activated by salient stimuli (it itches here!) and determine acts of self-care (scratch here!). ${ }^{29}$ Now, itches and the like can well be considered as the mildest forms of pain: they are phenomenally salient bodily disturbances with a location, an intensity, and dynamics; and we react by self-caring (scratching), perhaps to prevent an even more intense disturbance. So, even if is not necessary for a subject to recognize the mildest pain as such, there are phenomenal states that we would consider to be the mildest pains and that are phenomenologically recognized by all of us as such.

So far, I have been considering intensity, but a similar case can be made for location. The case for location is somehow different because it does not provide limits in the previous sense. However, recruiting the concept of "knowledge without observation" introduced by G.E.M. Anscombe (1957) and developed by Gareth Evans (1982) on the causal link between the source of pain and the phenomenal individuation of such a source, ${ }^{30}$ we can assign univocal locations to our pain sensations. Crucial here is the body map as a primitive source of knowledge. It is not necessary that the location be the correct one (referred and phantom pains are examples of incorrect locations with respect to the source of pain) but rather that it be univocally individuated. Basically, there is no need for any further property in order for one to have some conscious grasp of the location of her pain and to know that one has this experience.

Dynamics establish the general category to which a particular event of pain can belong. Burning or throbbing pains are recognized as such, in virtue of the phenomenology we directly experience, and tickling is the category to which itches belong. So, dynamics does not just combine location and intensity with a specific temporal pattern, rather it fixes the kind of pain we are acquainted with, also in virtue of the mentioned combination. The various adjectives we use to categorize our pains are

\footnotetext{
27 Relativized to our species, a threshold can be set where certain kinds of receptors or brain areas are activated. Generalizing: the threshold is set at the level where the species-specific receptors are activated. In this way, the limits are set structurally. I am indebted to Ricardo Santos for pressing me on this point.

28 For the concept of bodily disturbance, see Hill (2012).

29 The scratching takes the form of a response to a command, so satisfies what an original theory of pain - imperativism - indicates as the real content of this kind of states (Barlassina, \& Hayward 2019; Klein, 2015).

30 The problem of location is deeply connected to the issue of immunity to error through misidentification. I won't enter into this here, for a discussion see Gozzano (2019b).
} 
the result of our immediate experience, and from this the analysis in terms of intensity plus location follows. So, our experiences are somehow holistic, rather than analytic, and the epistemology of pain is a guide to its ontology (see Gozzano, 2020b).

Intensity, location, and dynamics (internal phenomenal roles) are anchoring phenomenal roles that provide the kind of self-individuation that Lowe was considering as an acceptable way out of the circularity objection. ${ }^{31}$ These self-identifying properties also have internal essential relations by analogy with those that obtain among numbers. These are relations such as being stronger than ... (on the intensity dimension) or being in the same area as ... (on the location dimension) and can be considered by analogy with an essential relation such as $\mathrm{x}+0=\mathrm{x}$ that characterizes $0 .^{32}$

I previously noted that the idea of external anchors being involved in the individuation conditions for pain states cannot be defended because of the multiple realizability objection. However, the proposal I am presenting is immune to the multiple realizability objection. First, the physical realizing states are associated with the phenomenal roles, they are not part of their individuation, which was my primary reason for individuating pain only through phenomenal roles. So, a change in the realizers does not modify the relations which constitute and individuate phenomenal roles themselves. The physical states that can be associated with the roles are those that satisfy the roles as they are, pretty much in analogy with the role/filler distinction imagined by Lewis (2009): phenomenal roles should be filled, and physical states are the occupants, the fillers, of those roles. Second, the physical states associated with a role form a second order equivalence set: the states belonging to the set are those that belong to one of the sets that warrant the realization of the relevant self-individuating properties (minimum threshold / maximal tolerance of pain) in some kind of individual. To clarify: consider Humans and Martians. The human states associated with the mildest pain are $\mathrm{Mh}_{1}, \mathrm{Mh}_{2}, \ldots \mathrm{Mh}_{\mathrm{n}}$, which all belong to kind Mh; those of Martians are $\mathrm{Mm}_{1}, \mathrm{Mm}_{2} \ldots \mathrm{Mm}_{\mathrm{n}}$, which all belong to kind $\mathrm{Mm}$. The role for the lightest pain is associated with the set $\{\mathbf{M h}, \mathbf{M m}\}$ and picks out $\mathbf{M h}_{\mathbf{j}}$ if humans are considered, $\mathbf{M m}_{\mathbf{j}}$ if Martians are.

So, we have individuated pain as a complex property with a structural net of roles reciprocally connected by being stimulated by salient stimuli and by causing the property of self-caring. Pain has some self-individuating roles: intensity, location and dynamics. My primary goal, which was to capture pain in dispositional terms, has been accomplished.

\footnotetext{
31 It might also be the case that external phenomenal roles have limits - for instance, the anxiety that one may have in thinking of pain may reach an upper limit-but I won't consider this aspect.

32 Note that, if identity theorists (such as Martin and Heil) are to retain their point of view, they have to accept that relational individuation is consistent with qualitativity (see Taylor, 2018). For a parallel with mathematics, see Barton (2020).
} 


\section{Pain as non-fundamental power}

We now need to show that pain is not a fundamental property, and to this end, we need to show that pain is physically realized. Individuating pain by a number of essential internal and external relations makes pain a dispositional property but does not secure its physical nature. For, as Taylor (2018) has stressed, dispositional properties are not, ipso facto, physical properties or, to put it otherwise, even if physical properties are dispositions, clearly it does not follow that dispositions are physical properties. The phenomenal roles, after all, could be dispositions which are not physical. Perhaps, they supervene on more fundamental powers that guarantee the structure and dynamics that they exhibit, where these powers, the "real ones", are physical. Alternatively, as Chalmers (1996) has argued, they could be fundamental but not physical properties, further elements of the basic structure of reality that have structure and dynamics as well (Chalmers, 2010). At the same time, these conscious states could not supervene on physical states. Consequently, if having structure and dynamics suffices to make something a disposition, pain could be a dispositional property but a fundamental one, with its own fundamental powers to exhibit. After all, one can even conceive of angels feeling pain, and angelical pain can be characterized in terms of angelical intensity, location, and dynamics, but none of these properties entail that such pain be physically realized in the ordinary senseonly in the angelical bodily sense. It is important to show, then, that pain is a nonfundamental disposition ready to fit within a physicalistic framework.

Chalmers (1996) has forcefully proposed that phenomenal properties be considered fundamental, also accepting the consequence of "outrageous" panpsychism. However, as he himself notes, that hypothesis plus the idea that phenomenal properties also have structure and dynamics, brings us toward the idea that there are properties constituting or correlated with the phenomenal properties we are accustomed to. These properties are called by Chalmers protophenomenal properties and described as "properties that collectively constitute phenomenal properties when organized in the appropriate way" (Chalmers, 2010: p. 151), and, regarding this collective constitution, "we need a much better understanding of the compositional principles of phenomenology: that is, the principles by which phenomenal properties can be composed or constituted from underlying phenomenal properties, or protophenomenal properties" (Ibid.: 136). So, it is natural to wonder whether the properties I have pointed out-intensity, location and dynamics—are protophenomenal properties that collectively compose or constitute the phenomenal property of pain. What are protophenomenal properties? Chalmers suggests that phenomenal properties might be non-fundamental properties that are necessitated by properties that, in turn, are not necessitated by physical properties (Chalmers, 2010: p. 125). At the same time, Chalmers, in discussing Russellian monism, takes protophenomenal properties to be "special properties that are not phenomenal (there is nothing it is like to have a single protophenomenal property) but that can collectively constitute phenomenal properties, perhaps when arranged in the right structure" (Chalmers, 
2015: p. 260). ${ }^{33}$ In arguing that pain, a phenomenal property, is a disposition individuated by three internal and two external roles, with internal relations that characterize their role essentially and not just by supervening on their components, I have paved the road for taking these roles to be the protophenomenal properties of pain. Chalmers imagines these properties to be a step toward solving the mind body problem by stressing that the " ... underlying neutral properties $X$ (the protophenomenal properties), [are] such that the $X$ properties are simultaneously responsible for constituting the physical domain (by their relations) and the phenomenal domain (by their collective intrinsic nature) ... [where] One could give the view in its most general form the name panprotopsychism, with either protophenomenal or phenomenal properties underlying all of physical reality." (Chalmers, 2010: p. 134). Now, Bird has argued that we cannot establish the existence of non-fundamental powers because these supervene on fundamental ones. If I'm right, the powers of phenomenal properties are robust enough, even if not fundamental.

Chalmers (2015) stresses that these protophenomenal properties are not experiential properties, there is nothing it is like to have them. At the same time, these necessitate phenomenal properties, which are fully experiential. So, there is a passage from the non-experiential to the experiential, or from the non-qualitative to the qualitative that some (to be determined) law or principle must explain. Now, unless endorsing the identity thesis by Molnar and Heil (which somehow resolve the problem by fiat) physicalism and property dualism appear to be in the same predicament: specify what the composition rules of these non-experiential properties need to be such that their effects are revealed in the phenomenal properties we directly experience. So, the supposed advantage of assuming phenomenal properties to be fundamental is lost: the same metaphysical job is to be done, but physicalism posits fewer fundamental properties. Moreover, we would need to provide an answer to the pressing question of what could stop us from thinking that the compositional rules are such that these protophenomenal properties need microphenomenal properties (which Chalmers invokes) and these, in turn, need nanophenomenal properties to justify their behavior, either seeping down endlessly or stopping at some phenomenal elementary particle, whatever that might be. It seems difficult to avoid this problem-as difficult as considering the suggestion of microphenomenal properties. On the other hand, taking protophenomenal properties to be those that necessitate the phenomenal one, is what this dispositional analysis need: the internal roles are necessary for pain as we experience it. Moreover, these internal roles cannot be quiddities: quiddities are contingently linked to their roles and so do not necessarily determine the phenomenal features of pain.

To assess the fundamentality of phenomenal properties, a different path could be followed. If a property is fundamental, it has a non-negotiable role in some law

\footnotetext{
33 While this paper was in preparation, a paper by Stoljar (2020) and a reply by Chalmers (2020) appeared. These discuss the relation between spatial functionalism-the view that spatiotemporal concepts can be analyzed in terms of their effects on phenomenal experience-and property dualism. It should be clear by now that my dispositionalist reading of pain based on phenomenal roles is tackling the same problem head on, by confronting a concept, pain, which finds no immediate room within a physicalistic framework.
} 
of nature. It follows that such a property is nomologically necessary for this world, because the laws of this world have been established with respect to the fundamental properties that exist, and phenomenal properties would be among them. At the current stage of scientific research, phenomenal properties could figure only in psychophysical laws, those that connect mental to physical properties. What fundamental relation could there be between these two kinds of properties? If the physical properties were not fundamental, we would have clear dependency relations of the physical on the mental; if both physical and mental properties were fundamental, we would have symmetrical relations, at least in some cases. What kind of relations do we observe between mental and physical properties when psychophysical laws are at stake? The most important instance of a psychophysical law is that concerning the relation between the subjective sense of the intensity of a stimulus and the intensity of the physical stimulus. The Weber-Fechner law took this relation to be logarithmic. The formulation of the law evolved because many revisions to the ratio between physical stimuli and subjective sense of intensity had been proposed. Stevens suggested that subjective intensity is related to the physical intensity of stimuli by a power law. MacKay has shown that the logarithmic and power laws are indistinguishable if the underlying neural mechanisms is not examined. Mountcastle showed that subjective intensity must be related linearly to the neural coding measure on which it is based. Finally, Johnson et al. (2002) -where you can find this very abridged history - demonstrated that the basic law of psychophysics is the linearity between subjective experience and the neural activity on which it is based. Here is their result: “... [the] subjective magnitude, $\mathrm{m}$, depends on a single, unidimensional measure, c, of the complex, multivariate neural response studied in the neurophysiological experiments: $m=m(c)$. [Where] $c=c(N)$, in which $c(N)$ is the function (the operation) that yields the neural coding measure, c. If, for example, $\mathrm{c}$ is the mean firing rate of a population of neurons, then $\mathrm{c}(\mathrm{N})$ is the operation, summation, required to obtain c." (Johnson et al. 2002: p. 113, my italics). This search for the dependency relation between phenomenal and physical signals makes it clear that the first, used as a heuristic guide, is taken to depend on the second, not the other way around. So, the relation between these two sets of properties is such that the physical variables determine the behavior of the mental variables inasmuch as the physical variable is taken to be the stimulus for which the mental variable is the dispositional manifestation.

One may critically observe: the way the linear function is described is not enough for showing the dependency of the phenomenal on the physical. ${ }^{34}$ After all, the physical is the result of the inverted function applied on the phenomenal. In order to reply, we should consider that there are aversive behaviors related to physical damages also in absence of conscious phenomena. Some animals are a case in point: it is possible that aversive behaviors are set with respect to damages to the body, actual or potential, without the presence of any phenomenal state. Phenomenal properties, then, would be attentional side-effects present in species which are capable of

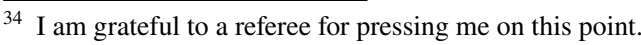


increasingly complex and sophisticated behaviors. ${ }^{35}$ So, phenomenal properties represent physical properties, and it would be counterintuitive to say that physical properties represent the phenomenal ones. Consequently, phenomenality allows us to track the causal profile of pain and it is grounded in the physical: there is an asymmetrical dependence in causal terms, even if, epistemologically speaking, phenomenality is better suited to keep track of damages. This asymmetry can be pointed out by considering the failure of the linearity correlation. Suppose to intervene on the correlation: if physical damages were to increase without a corresponding increase in the phenomenal intensity, the subject would suffer of a potentially fatal condition (as in congenital analgesia); if phenomenal intensity were to increase without a corresponding increase in the damages (as in hyperalgesia and in allodynia) the subject would not suffer of fatal effects. So, it is crucial that the phenomenal keeps track of the physical, not the other way around. Hence, the physical is ontologically prior with respect to the phenomenal. Am I dismissing the importance of phenomenality? Not at all: once phenomenality is in play it promotes a fine tuning in the causal profile of pain. Unless endorsing panpsychism, and so have mentality always and everywhere, the linearity function is set with respect to physical damages and whatever mechanism fits to react negatively and taking care of the damages. This converges to make the physical fundamental with respect to the mental. So, I keep my initial assumption and take phenomenal properties to be non-fundamental.

There is a further point to be noted with respect to psychophysical laws. We saw that physical (neural) properties do in fact result in pain. So, we are back to the dialectics of the relation between mental individuation and physical realization: pains are individuated via roles with further phenomenal properties, and these roles are physically realized. However, since we have captured the necessary protophenomenal components and relations for pain, we now have a deeper understanding of what we are looking for. The physical properties that realize pain have to fill all the roles individuating pain, including those played by the protophenomenal components. Now, the more the roles are specified, the more constraints are placed on the possible realizers of pain. The reason is that roles are constraints on realization. If a property is analyzed in terms of roles, being these structural or causal, these implicitly specify the set of possible realizers for the property itself. For, these roles are to be satisfied at once by one and the same realizers, even if the realizers may not undergo to all the possible causal relations that specify the property as such.

So, let's suppose that for a given phenomenal property it is possible to provide a maximal specification in terms of roles, where maximal specificity boils down to there being no further possible role that better specifies (or places further constraints on) what the given property is (or does). If such a maximal specification could be set, would it still allow for non-physical types of realization, those of an angelical sort? Here the crucial components are the external phenomenal roles, those that put our phenomenology in contact with the physical world as specified in the individuation conditions of pain. The individuation of an external phenomenal role is determined, as usual, by its overall relations; these comprise not only phenomenal

\footnotetext{
$\overline{35}$ For an interesting discussion of this point, from a different perspective, see Mørch (2017).
} 
properties, but also physical properties, such as physiological and behavioral reactions. These roles have to fit into physical roles as well, as the biochemistry of our physiology is part and parcel of biological, chemical and physical laws. Thus, the internal phenomenal roles, causing the external ones, are indirectly individuated by physical roles, so comply with the structure and dynamics of the latter. These external roles can be realized by type-different properties but, by further specifying the details of these roles, we reduce their possible realizers. Eventually, it is conceivable that these roles become so specific that very few, or possibly only one, realizers can fulfill the task. ${ }^{36}$ Clearly, if the very last option were the case, we would be a step closer to a type identification of mental and physical properties. Now that we have argued that pain is dispositional and non-fundamental, what is its overall causal role?

\section{The role of pain}

We established the idea that a property is substantially dispositional if it crucially figures in some law of nature. For, if no specific causal role is played, being dispositional could be the result of a mere façon de parler, a signpost for more robust explanations still to be devised. Even if the law in question supervenes on more basic laws - or if the properties figuring in these laws supervene on properties figuring in more basic laws - the role of the dispositional properties at stake should be necessary or counterfactual in themselves, so not amenable to reduction or being explained away. ${ }^{37}$ This feature supports the idea that these properties are natural or sparse even if not fundamental. Moreover, by figuring in laws, properties take on a unificatory role because they establish explanatory and causal roles which are to a large extent independent of their possible realizers. This means that modal fixity for non-fundamental properties should be compatible with multiple realizability. Thus, modal fixity should have a unifying function with respect to the different realizers (cfr. Vetter, 2018). Consequently, we cannot restrict our attention to the specific laws that are satisfied by the physical states and properties that happen to be the realizers of pain in our species. We should look for laws in which pain figures as a non-negotiable component. In this search, we should distinguish between the laws in which the various realizers for pain are present, and what these laws have in common. ${ }^{38}$ The laws of pain we are after are those that hold with a certain degree of independence with respect to the differences determined by the various realizers. Just as there are laws or principles that all spherical objects share independently

\footnotetext{
36 As examples of realization, consider the intensity limiting points: minimal pain when endorphins are released; at least $50 \%$ of stimuli in the area are perceived as nocive / maximal, e.g., the subject faints. These realizers characterize the physically sparse structure of pain, determining that some phenomenal roles are associated with an established position in the physical net. These physiological realizers may change from world to world, but the issue is analogous to the referring function of "the winning number of this week's lottery" by Lewis: this referent may change as token, but its abstract type remains constant.

37 At least in the actual world.

38 As with the subset strategy, see Shoemaker (2001) and Wilson (2011).
} 
from their type-different realizations (spheres made of steel and made of wood roll, more or less, similarly), we should look for laws that hold at a more general and abstract level.

What is essential and unificatory about pain is its overall biological role: pain has a crucial function in preserving life. When the lives of animals-even invertebrates - are at stake, their survival essentially depends on a system for pain, a system that orients the attention of the animal to phenomenologically salient stimuli, stimuli that may threaten, disturb, damage, or destroy its life-supporting structures, organs and systems and that forces the animal to undertake self-caring reactions of some kind, such as caring for bodily injury, and preventing further potential damages. In this, I am following what some neuroscientists observe: "It is generally recognized that the ability to detect, reorient attention and prioritize the cortical processing of salient sensory input is crucial for survival ... Because of their noxious nature, nociceptive stimuli have intrinsically high saliency content, and for this reason, this ability to detect and react to salient sensory input is often considered as one of the most important function of nociception" (Iannetti, \& Mouraux 2010: p. 7). This function of preserving life captures the role, and hence unifies, all the realizers of pain, making it a relatively crucial function. It is relatively crucial inasmuch as it has to be realized, but it is crucial inasmuch it characterizes a number of natural kinds, if biological species are so considered.

At the same time, the functions mentioned above (detecting and signaling any salient stimulus, actually or potentially disturbing or damaging and forcing or pushing the animal toward self-care), are part of the external phenomenal roles and all living beings must have such a system or risk not surviving. The current scientific hypothesis is that in humans this system is realized in a Pain Matrix (as a development of the Neuromatrix), whose primary structures are the primary (S1) and secondary (S2) somatosensory cortices, the insula, and the anterior cingulate cortex (ACC). Hypothetically, S1 and S2 (the lateral pain system) encode the somatosensory perception of pain, while ACC (the medial pain system) encodes its affective dimension. Supposing there is such a Matrix, and that it is specific for pain, the laws in which such a matrix is necessarily involved constitute the core of a dispositional interpretation of modal fixity. ${ }^{39}$

The laws in which pain figures are those that supervene on the laws relating its specific and various realizers. If these realizers are type-different, as one should assume in order to ensure robust multiple realizability, and become part of psychophysiological laws, then the supervening laws in which pain plays a non-negotiable role, should hold independently of the physical details of the various realizers. If this is the case, this means that pain is playing a substantial causal role as a nonfundamental power.

\footnotetext{
39 Such matrix works as a high-level detection-reaction system, one that is captured by considering its overall biological function: "This cortical network might represent a basic mechanism through which significant events for the body's integrity are detected, regardless of the sensory channel through which these events are conveyed" (Legrain et al. 2011: p. 111).
} 
To conclude, in this paper I have argued that bodily pain is essentially individuated by its phenomenal roles. It is thus a dispositional property and it is essentially so, in that there can't be pains which do not have the roles and the internal relations between them I have discussed. These roles are associated with a set of possible physical realizers and such realizers play the causal roles of pain in biological terms. So, the phenomenal roles of pain, as captured by the relevant causal laws, are independent of specific realizations and are not fundamental but play a relatively crucial role for survival. Hence pain is an essentially dispositional property with a substantial causal role to play, as I promised to argue.

Acknowledgements A number of people help me in improving this paper. I would like to thank Umut Baysan, Donatella Donati, Giorgio Lando, Paul Noordhof, Hili Ratzinsky, Marco Segala and audience at conferences in L'Aquila, Lisbon, Turin and Durham-Oxford. Last but not least, I express my gratitude to two anonymous reviewers for this journal for their helpful comments.

Funding Open access funding provided by Università degli Studi dell'Aquila within the CRUI-CARE Agreement.

Open Access This article is licensed under a Creative Commons Attribution 4.0 International License, which permits use, sharing, adaptation, distribution and reproduction in any medium or format, as long as you give appropriate credit to the original author(s) and the source, provide a link to the Creative Commons licence, and indicate if changes were made. The images or other third party material in this article are included in the article's Creative Commons licence, unless indicated otherwise in a credit line to the material. If material is not included in the article's Creative Commons licence and your intended use is not permitted by statutory regulation or exceeds the permitted use, you will need to obtain permission directly from the copyright holder. To view a copy of this licence, visit http://creativecommons.org/licen ses/by/4.0/.

\section{References}

Anscombe, G. E. M. (1957). Intention. Cornell University Press.

Armstrong, D. (1997). A world of states of Affairs. Cambridge University Press.

Bain, D. (2013). What makes pains unpleasant? Philosophical Studies, 166, 69-89

Barlassina, L., \& Hayward, M. (2019). More of me! Less of me!: Reflexive imperativism about affective phenomenal character. Mind, 128, 1013-1044

Barton, N. (2020). Absence perception and the philosophy of zero. Synthese, 197, 3823-3850

Bayne, T. (2010). The unity of consciousness. Oxford University Press.

Baysan, U. (2018). Mad qualia. The Philosophical Quarterly, 69, 467-485

Bird, A. (2007a). Nature's metaphysics. Oxford University Press.

Bird, A. (2007b). The regress of pure powers. The Philosophical Quarterly, 57, 513-534

Bird, A. (2016). Overpowering: How the powers ontology has overreached itself. Mind, 125, 341-383

Bird, A. (2018). Fundamental powers, evolved powers, and mental powers. Proceedings of the Aristotelian Society Supplementary, 92, 247-275

Block, N. (1980). "What is functionalism? In N. Block (Ed.), Readings in philosophy of psychology. (pp. 171-184). Harvard University Press.

Carnap, R. (1936). Testability and meaning. Philosophy of Science, 3, 419-471

Choi, S. (2012). Intrinsic finks and dispositional/categorical distinction. Noûs, 46, 289-325

Carruth, A. (2016). Powerful qualities, zombies and inconceivability. The Philosophical Quarterly, 66, $25-46$

Chalmers, D. (1996). The conscious mind. Oxford University Press.

Chalmers, D. (2010). The character of consciousness. Oxford University Press. 
Chalmers, D. J. (2015). Panpsychism and panprotopsychism. In A. Torin \& Y. Nagasawa (Eds.), Consciousness in the physical world: Perspectives on Russellian Monism. (pp. 246-276). Oxford University Press.

Chalmers, D. (2020). Spatiotemporal functionalism vs. the conceivability of zombie. Noûs. https://doi. org/10.1111/nous. 12331

Contessa, G. (2019). Powerful qualities or pure powers? Metaphysica, 20(1), 5-33

Ellis, B. (2001). Scientific Essentialism. Cambridge University Press.

Evans, G. (1982). The varieties of reference. Clarendon Press.

Fara, M. (2005). Dispositions and habituals. Noûs, 39, 43-82

Goldstein, I. (1983). Pain and masochism. Journal of Value Inquiry, 17, 219-223

Gozzano, S. (2019a). Beliefs as mental states: Steps toward a dispositional approach. Rivista di Filosofia, $110,201-219$

Gozzano, S. (2019b). Locating and representing pain. Philosophical Investigation, 42, 313-332

Gozzano, S. (2020a). Necessitarianism and dispositions. Metaphysica, 21, 31-53

Gozzano, S. (2020b). The dispositional nature of phenomenal properties. Topoi, 39, 1045-1055

Grahek, N. (2007). Feeling pain and being in pain. MIT Press.

Iannetti, G., \& Moureaux, A. (2010). From the neuromatrix to the pain matrix (and back). Experimental Brain Research, 205, 1-12

Heil, J. (2003). From an ontological point of view. Oxford University Press.

Heil, J. (2012). The Universe as we find it. Clarendon Press.

Hildebrand, T. (2015). Two types of quidditism. Australasian Journal of Philosophy, 94, 1-17

Hill, C. (2012). Locating qualia: Do they reside in the brain or in the body and the world? In S. Gozzano \& C. Hill (Eds.), New perspectives on type-identity. (pp. 127-149). Cambridge University Press.

Horgan, T. (1984). Functionalism, qualia, and the inverted spectrum. Philosophy and Phenomenological Research, 44, 453-469

Hornsby, J. (1986). Physicalist thinking and conceptions of behaviour. In P. Pettit \& J. McDowell (Eds.), Subject, thought and context. (pp. 111-128). Oxford University Press.

IASP-International Association for the Study of Pain (1986). Pain Terms: A list with definitions and notes on pain. Pain, Vol. 3 (Suppl.), pp. 216-21. www.iasp-pain.org.

Ingthorsson, R. D. (2013). Properties: Qualities, powers, or both? Dialectica, 67, 55-80

Jacobs, J. (2011). Powerful qualities, not pure powers. The Monist, 94, 81-102

Johnson, K., Hsiao, S. Y., \& T. . (2002). Neural coding and the basic law of psychophysics. The Neuroscientist, 8(2), 111-121

Kim, J. (2005). Physicalism, or something near enough. Princeton.

Klein, C. (2014). The penumbral theory of masochistic pleasure. Review of Philosophy and Psychology, $5,41-55$

Klein, C. (2015). What the body commands. MIT Press.

Kriegel, U. (2012). The sources of intentionality. Oxford University Press.

Langsam, H. (2011). The wonder of consciousness: Understanding the mind through philosophical reflection. MIT Press.

Legrain, V., Iannetti, G. D., Plaghki, L., \& Mouraux, A. (2011). The pain matrix reloaded. A salience detection system for the body. Progress in Neurobiology, 93, 111-124

Lewis, D. (1970). How to define theoretical terms. The Journal of Philosophy, 67, 427-446

Lewis, D. (1972). Psychophysical and theoretical identifications. Australasian Journal of Philosophy, 50, 249-258

Lewis, D. (1980). Mad pain and Martian pain. In N. Block (Ed.), Readings in the philosophy of psychology. (pp. 216-222). Harvard University Press.

Lewis, D. (2009). Ramseyan Humility. In D. B. Mitchell \& R. Nola (Eds.), Conceptual analysis and philosophical naturalism. (pp. 203-222). MIT Press.

Lowe, E. J. (2006). The four-category ontology. Oxford University Press.

Lowe, E. J. (2012). Asymmetrical dependence in individuation. In F. Correia \& M. Schneider (Eds.), Metaphysical grounding. (pp. 214-233). Cambridge University Press.

Martin, C. B. (2008). The mind in nature. Oxford University Press.

Martin, C. B., \& Heil, J. (1999). The ontological turn. Midwest Studies in Philosophy, 23, 34-60

Massin, O. (2017). "Bad by nature: An axiological theory of pain. In J. Corns (Ed.), The Routledge handbook of philosophy of pain. Routledge.

Mendelovici, A. (2018). The phenomenal basis of intentionality. Oxford University Press.

Molnar, G. (2003). Powers: A study in metaphysics. Oxford University Press. 
Mørch, H. H. (2017). The evolutionary argument for phenomenal powers. Philosophical Perspectives, 31(1), 293-316

Mørch, H. H. (2020). The phenomenal powers and the meta-problem of consciousness. Journal of Consciousness Studies, 27(5-6), 131-142

Mumford, S. (1998). Dispositions. Clarendon Press.

Mumford, S., \& Anjum, R. (2011). Getting causes from powers. Oxford University Press.

Ramachandran, V. S. (1998). Consciousness and body image: Lessons from phantom limbs, Capgras syndrome and pain asymbolia. Philosophical Transaction of the Royal Society B: Biological Sciences., 353, 1851-1859

Schaffer, J. (2005). Quidditistic knowledge. Philosophical Studies, 123, 1-32

Schwitzgebel, E. (2002). A phenomenal, dispositional account of belief. Noûs, 36, 249-275

Shoemaker, S. (1980). Causality and properties. In J. Kim \& E. Sosa (Eds.), Metaphysics. An anthology. (pp. 253-268). Blackwell.

Shoemaker, S. (2001). Realization and mental causation. In C. Gillet (Ed.), Physicalism and its discontents. (pp. 74-98). Cambridge University Press.

Stoljar, D. (2020). Chalmers v. Chalmers. Noûs, 54(2), 469-487

Swinburne, R. (1980). Properties, causation and projectability: Reply to shoemaker. In J. Cohen \& M. Hesse (Eds.), Applications of Inductive Logic. (pp. 313-320). Clarendon Press.

Tugby, M. (2013). Platonic dispositionalism. Mind, 122, 451-480

Taylor, J. (2013). In defence of powerful qualities. Metaphysica, 14, 93-107

Taylor, J. (2018). Powerful qualities and pure powers. Philosophical Studies, 175(6), 1423-1440

Tye, M. (1989). The metaphysics of mind. Cambridge University Press.

Vetter, B. (2015). Potentiality: From dispositions to modality. Oxford University Press.

Vetter, B. (2018). Evolved powers, artefact powers, and dispositional explanations. Proceedings of the Aristotelian Society Supplementary, 92, 276-297

Yates, D. (2018). Inverse functionalism and the individuation of powers. Synthese, 195, 4525-4550

Wang, J. (2016). The nature of properties: Causal essentialism and quidditism. Philosophy Compass, 11(3), 168-176

Wilson, J. (2011). Non-reductive realization and the power-based subset strategy. The Monist, 94, $121-154$

Publisher's Note Springer Nature remains neutral with regard to jurisdictional claims in published maps and institutional affiliations. 